\title{
Malaria epidemiology in the State of Piauí, Northeastern Brazil: a retrospective study with secondary data
}

\author{
Joyce Anny Alves do Nascimento ${ }^{[1],[2], ~ L u c a s ~ M e l o ~ G u i m a r a ̃ e s ~}{ }^{[1],[2]}$ \\ and Filipe Anibal Carvalho-Costa ${ }^{[1],[3]}$
}

[1]. Laboratório de Epidemiologia e Sistemática Molecular, Instituto Oswaldo Cruz, Fundação Oswaldo Cruz, Rio de Janeiro, Rio de Janeiro, Brasil. [2]. Programa de Pós-graduação em Medicina Tropical, Instituto Oswaldo Cruz, Fundação Oswaldo Cruz, Rio de Janeiro, Rio de Janeiro, Brasil. [3]. Escritório Técnico Regional, Fundação Oswaldo Cruz, Teresina, Piauí, Brasil.

\begin{abstract}
Introduction: Malaria is not considered endemic in State of Piauí. Methods: Malaria epidemiology was examined using surveillance data. Results: During 2002-2013, of the 484 cases of malaria, 217 were classified as probably acquired in Piauí, most frequently in the Campo Largo, Buriti dos Lopes, and Luzilândia municipalities, and 267 were considered probably imported, from the States of Pará, Maranhão, Amazonas, Roraima, and Rondônia. Probably-imported cases occurred throughout the year, while $80.2 \%$ of the probably-acquired cases occurred in April-August, peaking at the end of the rainy season. Conclusions: Malaria surveillance should be intensified. Further ecoepidemiological and entomological studies are needed.
\end{abstract}

Keywords: Epidemiology. Malaria. health surveillance.

In 2014, 138,295 cases of malaria were recorded in Brazil, almost all of which occurred in the Amazon region. This region includes the States of Acre, Amapá, Amazonas, Maranhão, Mato Grosso, Pará, Rondônia, Roraima, and Tocantins ${ }^{(1)}$. Nevertheless, extra-Amazonian malaria cases have attracted the attention of the epidemiological surveillance system ${ }^{(2)}$. In Brazil, extraAmazonian malaria cases can be attributed to the emigration of individuals with malaria from Amazonian states to nonendemic regions, introduction of Plasmodium into mosquito populations in receptive regions by parasitemic individuals coming from endemic regions, and/or transmission in the Atlantic Forest by the bromeliad mosquito Anopheles (Kerteszia) cruzii (2). In Brazil, Plasmodium vivax and P. falciparum cause approximately $84 \%$ and $16 \%$ of all malaria cases, respectively ${ }^{(3)}$.

Patients with suspected malaria in endemic states are handled by an extensive network of governmental diagnostic and treatment centers ${ }^{(4)}$. Diagnosis is performed with Giemsastained thick blood smears, and antimalarial drugs are provided free of charge for any positive case. Usually, a second blood examination is provided after treatment to confirm that the case was cured. The incidence of malaria has exhibited a downward trend in recent years, since more than 300,000 malaria cases were reported in $2009^{(1)}$. However, major operational difficulties persist, related with political issues, administrative gaps, and the unique ecological and socio-demographic characteristics of the Amazon region ${ }^{(5)(6)(7)}$.

Corresponding author: Dr. Filipe Anibal Carvalho-Costa.

e-mail: guaratiba@ioc.fiocruz.br

Received 11 May 2015

Accepted 22 September 2015
The capacity to effectively manage malaria in the Brazilian Amazon is already present. Although few extra-Amazonian cases occur, they nevertheless represent an extremely important problem because they occur in regions in which the disease is poorly understood by both the population and health personnel $^{(8)(9)(10)}$. This lack of understanding can delay diagnosis, increase the case fatality rate, and allow the persistence of parasitemic individuals in nonendemic areas. Some areas are potentially receptive to maintenance of autochthonous malaria transmission because they harbor Anopheles species that exhibit good vectorial capacity. In addition, many of these areas are vulnerable because of migrants with parasitemia from endemic regions. In this context, extra-Amazonian cases of malaria are becoming increasingly important and represent a major challenge to health authorities.

States in Northeastern Brazil, with the exception of Maranhão, which has part of its territory in the Amazon, are considered nonendemic and generally report only sporadic or imported malaria cases. As a result, limited data have been published regarding malaria in the State of Piauí. This study aimed to describe the epidemiological aspects of malaria in Piauí, with an emphasis on spatio-temporal trends.

The State of Piauí is located in the mid-northern region of northeastern Brazil. This region represents a confluence of distinct biomes, specifically semiarid caatinga to the east, cerrado to the south, and pre-Amazonian rainforest to the west. Thus, the climate varies between tropical and semi-arid, with high temperatures ranging from 28 to $39^{\circ} \mathrm{C}$. A marked rainy season occurs in the first semester. Piauí has 3,194,718 inhabitants and an area greater than $251,577 \mathrm{~km}^{2}$. The state has the lowest gross domestic product per capita in Brazil. 
Malaria is an obligatory notifiable disease in Brazil. Data from the System of Information for Notification Diseases (SINAN) were retrospectively reviewed to characterize the geographic and temporal distributions of malaria cases reported in Piauí from 2002 to 2013. Each case was confirmed by parasitological diagnosis using thick blood smears. Cases were included only if the Giemsa-stained thick blood smears were positive for P. vivax, P. falciparum, or P. malariae. Only malaria cases with well-established parasite-specific positive thick blood smears were included.

Climatic data were obtained from the National Meteorology Institute (INMET) at http://www.inmet.gov.br/ (accessed April $15^{\text {th }}, 2015$ at 2:00 PM). The maximum temperatures, minimum temperatures, and precipitation levels were retrieved; monthly averages were calculated for the 2002-2013 period. The selected climate data were obtained at an INMET station $\left(3^{\circ} 27^{\prime} 40^{\prime \prime} \mathrm{S} / 42^{\circ} 22^{\prime} 18^{\prime \prime} \mathrm{W}\right)$ near the cities at which the highest numbers of cases were recorded.

All suspected (probable) infection sites were reported on the notification forms. However, it is not possible for the agents responsible for this information to perform a systematic search to definitively establish where each patient was infected with malaria. Agents are limited to asking where each patient has traveled in recent weeks and if he/she is returning from a known malaria-endemic region. Thus, in this study, cases were classified into the following categories: probably acquired in Piauí, if the reported infection site was a municipality belonging to the State of Piauí, or probably imported, if the infection site reported in the notification form was a municipality outside Piauí.

Malaria cases were distributed by month, year, geographic location (probable site of infection), and demographic characteristics. Spatial distribution was performed with QGIS (QGIS Development Team, available at http://www.qgis.org/en/ site/). Statistical analyses were performed with SPSS ${ }^{\circledR}$ (IBM Corp., Armonk, NY, USA). Data are presented as descriptive statistics, and the characteristics of probably acquired versus probably imported cases were compared using the chi-square test. Statistical significance was set at 5\%.

This study was approved by the Ethics Research Committee at Oswaldo Cruz Institute/FIOCRUZ, license number 39405514700005248.

From 2002 to 2013, 484 parasitologically confirmed cases of malaria were recorded. Of these, 217 cases were likely acquired in Piauí, and 267 cases were probably imported. The positive thick blood smear results were as follows: P. falciparum, $\mathrm{n}=86(17.8 \%) ;$ P. falciparum with gametocytes, $\mathrm{n}=7(1.4 \%)$; P. vivax, $\mathrm{n}=362(74.8 \%) ;$ P. falciparum + P. vivax, $\mathrm{n}=25$ $(5.2 \%) ;$ P. vivax + P. falciparum gametocytes, $\mathrm{n}=2(0.4 \%)$; and $P$. falciparum gametocytes, $\mathrm{n}=2(0.4 \%)$. The proportions of infection with P. falciparum among the probably-acquired cases and probably-imported cases were $13.8 \%$ and $34.4 \%$, respectively $(p<0.001)$. The monthly and annual distributions of malaria cases, including the variation in the proportions of P. falciparum infection, are shown in Figures 1A and 1B. While the probably-imported cases occurred throughout the year,
$80.2 \%$ of the cases classified as probably acquired occurred from April to August. A marked increase in the number of cases was observed in 2004. The climatic characteristics are displayed in Figure 2 and reveal that the number of the probably-acquired cases increased at the end of the rainy season in the state.

Cases probably acquired in Piauí (probable site of infection) were reported most frequently in the municipalities of Campo Largo do Piauí ( $\mathrm{n}=70$ [32.3\%]), Buriti dos Lopes $(\mathrm{n}=25$ [11.5\%]), Luzilândia $(n=24$ [11\%]), Uruçuí $(n=12$ [5.5\%]), and Porto $(n=11[3.1 \%])$. The cities that recorded the highest numbers of probably-acquired malaria cases are located on the banks of the Parnaíba River, bordering the State of Maranhão (Figure 3A). In contrast, the majority of the probably-imported cases were reported in the States of Pará $(\mathrm{n}=90$ [33.7\%]), Maranhão ( $\mathrm{n}=51$ [19.1\%]), Amapá $(\mathrm{n}=12$ [4.5\%]), and Amazonas ( $\mathrm{n}=11[4.1 \%])$. The probable sites (municipalities) of infection for the imported cases are presented in Figure 3B.

The proportions of cases probably acquired and probably imported in children aged $0-12$ years were $18.4 \%(\mathrm{n}=40)$ and $3.4 \%(\mathrm{n}=9)$, respectively $(\mathrm{p}<0.001)$. The proportions of probably-acquired and probably-imported cases in women were $34.6 \%(\mathrm{n}=75)$ and $16.9 \%(\mathrm{n}=45)$, respectively $(\mathrm{p}<0.001)$.

Extra-Amazonian cases of malaria have been reported in Brazil; consequently, the surveillance of such cases has increased $^{(2)}$. Although the State of Piauí is situated outside the Amazon, it borders Maranhão and Tocantins, two states located in the Amazonian region. These two states have active transmission of malaria ${ }^{(11)(12)}$.

As presented here, Piauí records an average of approximately 40 malaria cases per year, nearly half of which are probably acquired in the state, i.e., are potentially autochthonous. Almost all of these cases were reported in the counties that border Maranhão; the Parnaíba River separates these two states. The middle-North region of Brazil is an extensive ecotone zone between the sub-humid pre-Amazonian region, Cerrado biome, and semi-arid Northeast. This region has an extensive network of drainage with the Parnaíba River as its main body of water. Piauí has remnants of the Atlantic Forest in its Northwestern region where many malaria cases were reported as well as in the central Southern region.

Entomological surveys performed in Piauí aimed at characterizing the local Anopheles species have provided interesting findings. The most recent of these data were acquired from 2000 to 2010. These surveys reported the presence of the Anopheles species in the Amazon region (An. darlingi) and in northeastern Brazil (An. albitarsis, An. aquasalis), confirming the transitional character of the middle-North region of Brazil. In this context, An. darlingi has been identified in 85 municipalities ranging from the North to the South of Piauí, mainly in the western area of the state. An. albitarsis has been observed in 97 municipalities, mainly in Eastern Piauí, whereas An. aquasalis has been captured in two coastal municipalities in the north. Captures of primary malaria vectors have been documented in $50.2 \%$ of all the municipalities in Piauí (Coordenação de Vigilância em Saúde Ambiental/Secretaria de Estado de Saúde do Piaui, unpublished data). Similar data were reported in 


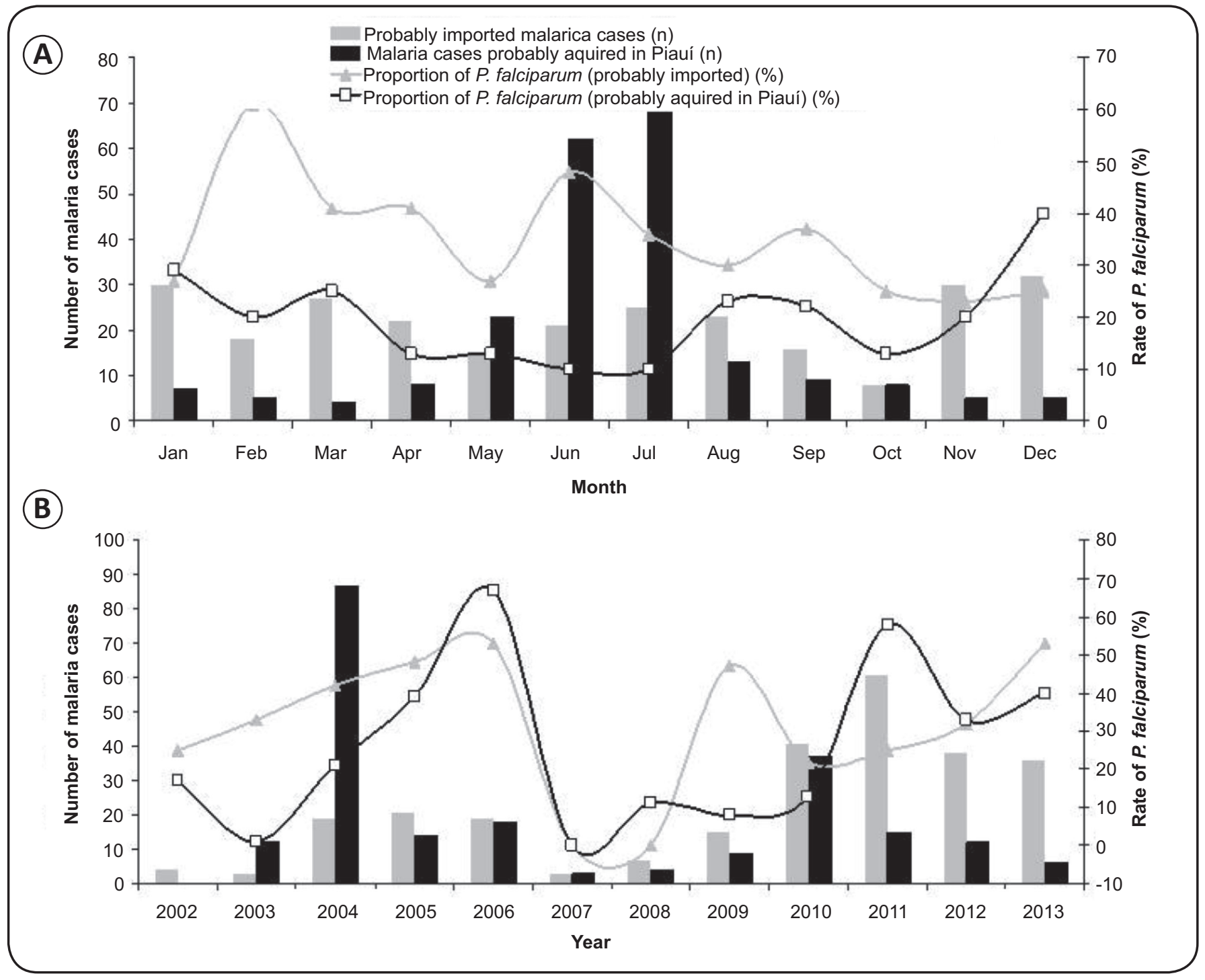

FIGURE 1 - Monthly distributions, annual distributions, and proportions of malaria cases caused by Plasmodium falciparum reported in the State of Piauí, Northeastern Brazil, between 2002 and 2013.

the State of Maranhão, illustrating the broad diversity of the Anopheles species in this transitional zone ${ }^{(13)}$.

The present study demonstrated that cases probably acquired in municipalities belonging to the state of Piauí exhibit distinct transmission dynamics of probably imported malaria. Moreover, a well-marked seasonality of probably autochthonous malaria was observed; specifically, the incidence increased at the end of the rainy season. Greater proportions of probably autochthonous cases compared with imported cases in women and children are also characteristic of this autochthonous pattern. Imported cases tend to occur more frequently in adult men, probably within an occupational context related to the migration of the workforce to and from Amazonian states in which malaria is endemic. The probable infection sites of most cases considered to be imported were in the South of Pará and in Rondônia, as well as in Manaus (the state capital of Amazonas) and Roraima. Thus, many subjects are likely to have been infected in areas with high incidences of malaria that are also associated with agriculture (including cattle raising), mining projects, and hydropower plant construction in the Amazon. These Amazonian areas continue to import members of the workforce from impoverished regions in northeastern Brazil. Many of these workers may have malaria when they return to their home cities in Piauí. Individuals with asymptomatic parasitemia coming from the Amazon can be an interface between introduced and autochthonous malaria because they represent a source of Plasmodium infection for the vectors. In this sense, the presence of parasitemic asymptomatic individuals during the period of increased vector density potentially produces autochthonous cases. The importance of asymptomatic and submicroscopic infections for transmission maintenance, as well as the need to improve diagnostic tools, has been demonstrated in different regions, as recently reviewed by Bousema et al. ${ }^{(14)}$. In this sense, Piauí is particularly receptive to malaria, as well as quite vulnerable due to its proximity to endemic states and the migratory flux of workers to the Amazon. 


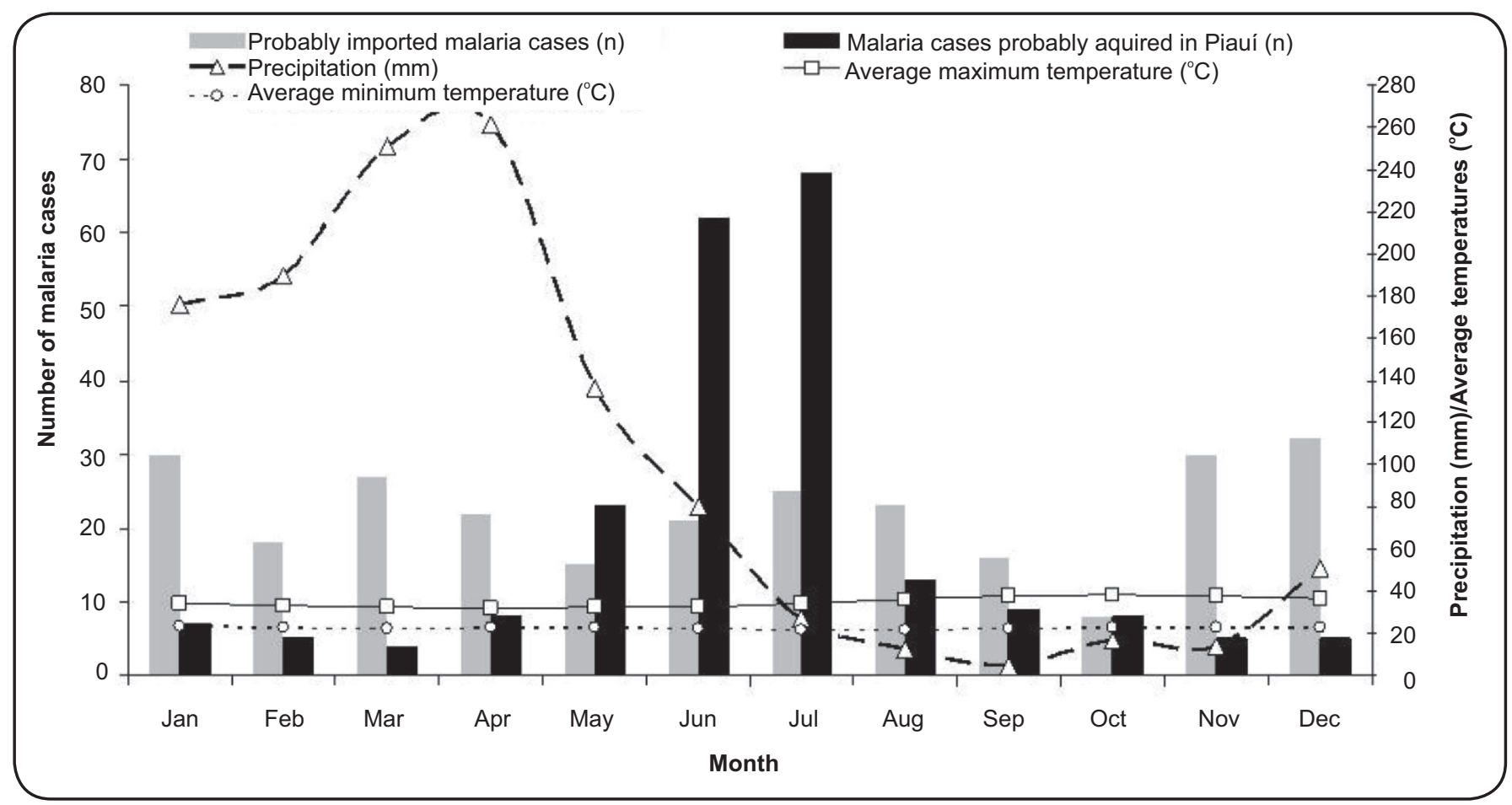

FIGURE 2 - Climatic characteristics and monthly distributions of malaria cases reported in the State of Piauí, Northeastern Brazil, between 2002 and 2013.

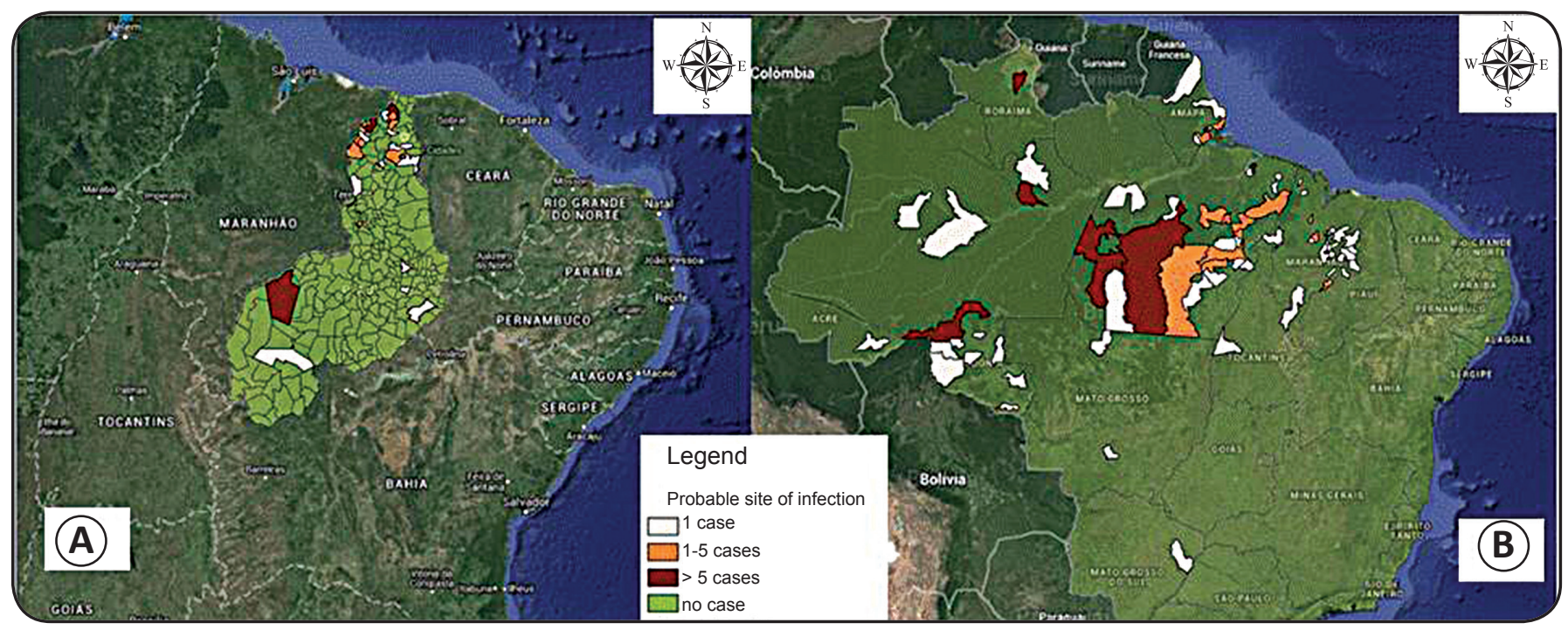

FIGURE 3 - Maps showing the probable municipalities of infection for malaria cases reported in the State of Piauí between 2002 and 2013.

A marked increase in malaria incidence was observed in 2004, a year in which 70 cases were reported in the municipality of Campo Largo do Piauí during May, June, and July. All of these cases were considered to be acquired in the state and were not preceded by the notification of imported cases. However, one study proposed that this outbreak was related to the arrival of parasitemic clandestine gold prospectors from Suriname, an endemic country ${ }^{(2)}(15)$.
Health care and epidemiological surveillance teams should be alerted to the presence of malaria in Piauí so that they can provide immediate treatment, improve patient prognoses, and reduce the maintenance of parasitemic individuals in the region. Moreover, Anopheles breeding sites should be identified and appropriately managed, especially in municipalities with high numbers of cases. 


\section{CONFLICT OF INTEREST}

The authors declare that there is no conflict of interest.

\section{FINANCIAL SUPPORT}

This study comprises the work towards a Master's Degree in Tropical Medicine at the Oswaldo Cruz Foundation (FIOCRUZ)/ Brazilian Ministry of Health for J.A.A. do Nascimento. Funding was provided by FIOCRUZ, Brazilian Ministry of Health. We thank Dr. Lindsay Carpp (Center for Infectious Disease Research, Seattle, WA) for English editing and critical revision of the manuscript.

\section{REFERENCES}

1. Portal da Saúde do SUS. Situação Epidemiológica - Dados; 2015. (Accessed 2015 May 05). Available at: portalsaude.saude.gov.br

2. de Pina-Costa A, Brasil P, Di Santi SM, de Araujo MP, SuárezMutis MC, Santelli AC, et al. Malaria in Brazil: what happens outside the Amazonian endemic region. Mem Inst Oswaldo Cruz 2014; 109:618-633.

3. Oliveira-Ferreira J, Lacerda MV, Brasil P, Ladislau JL, Tauil PL, Daniel-Ribeiro CT. Malaria in Brazil: an overview. Malar J 2010; 9:115.

4. Cabral AC, Fé NF, Suárez-Mutis MC, Bóia MN, Carvalho-Costa FA. Increasing incidence of malaria in the Negro River basin, Brazilian Amazon. Trans R Soc Trop Med Hyg 2010; 104:556-562.

5. Hahn MB, Gangnon RE, Barcellos C, Asner GP, Patz JA. Influence of deforestation, logging, and fire on malaria in the Brazilian Amazon. PLoS One 2014; 9:e85725.

6. Da Silva-Nunes M, Moreno M, Conn JE, Gamboa D, Abeles S, Vinetz JM, et al. Amazonian malaria: asymptomatic human reservoirs, diagnostic challenges, environmentally driven changes in mosquito vector populations, and the mandate for sustainable control strategies. Acta Trop 2012; 121:281-291.

7. Peiter PC, Franco VC, Gracie R, Xavier DR, Suárez-Mutis MC. Malaria in the triple border region between Brazil, Colombia and Peru. Cad Saude Publica 2013; 29:2497-2512.

8. Maselli LM, Levy D, Laporta GZ, Monteiro AM, Fukuya LA, Ferreira-da-Cruz MF, et al. Detection of Plasmodium falciparum and Plasmodium vivax subclinical infection in non-endemic region: implications for blood transfusion and malaria epidemiology. Malar J 2014; 13:224.

9. Pedro RS, Guaraldo L, Campos DP, Costa AP, Daniel-Ribeiro CT, Brasil P. Plasmodium vivax malaria relapses at a travel medicine centre in Rio de Janeiro, a non-endemic area in Brazil. Malar J 2012; 11:245.

10. Costa AP, Bressan CS, Pedro RS, Valls-de-Souza R, Silva S, Souza PR, et al. Delayed diagnosis of malaria in a dengue endemic area in the Brazilian extra-Amazon: recent experience of a malaria surveillance unit in state of Rio de Janeiro. Rev Soc Bras Med Trop 2010; 43:571-574.

11. Parise ÉV, Araújo GC, Castro JG, Berdarrain FP. Epidemiological profile of malaria in the state of Tocantins, Brazil, from 2003 to 2008. Rev Inst Med Trop Sao Paulo 2011; 53:141-147.

12. Raposo CC, Santos JB, Santos GM, Gonçalves EG, Silva AR. Plasmodium vivax malaria: related factors to severity in the State of Maranhao, Brazil. Rev Soc Bras Med Trop 2013; 46:67-72.

13. Rebêlo JMM, Morais JLP, Alves GA, Leonardo FS, Rocha RV, Mendes WA, et al. Distribution of species from genus Anopheles (Diptera, Culicidae) in the State of Maranhão, Brazil. Cad Saude Publica 2007; 23:2959-2971.

14. Bousema T, Okell L, Felger I, Drakeley C. Asymptomatic malaria infections: detectability, transmissibility and public health relevance. Nat Rev Microbiol 2014; 12:833-840.

15. Chagas MFB, Feitosa HP, Souza RMS, Costa MA. Malária: uma endemia (re)emergente no Piauí? Rev Soc Bras Med Trop 2005; 38 (suppl I): 329. 